\title{
An Update on Drug-eluting Technology in Peripheral Arteries to Treat Peripheral Arterial Disease
}

\author{
Leonardo Marques, Silke Hopf-Jensen, Michael Preiss and Stefan Mueller-Huelsbeck \\ Department of Diagnostic and Interventional Radiology/Neuroradiology, Academic Hospitals Flensburg, Flensburg, Germany
}

DOI: https://doi.org/10.17925/HI.2021.15.2.73

$\mathrm{F}$ or the treatment of peripheral arterial disease, drug-eluting technology is a widely accepted therapeutic option, with significant reduction in intimal hyperplasia and, consequently, use of target lesion revascularization. Nevertheless, the reputation of such devices was damaged after a meta-analysis, published in December 2018, showed increased mortality in patients receiving paclitaxel-eluting devices. Although subsequent studies have failed to establish such correlation, the use of paclitaxel-eluting devices remains heavily restricted. As such, other options and drugs have been developed, for instance sirolimus. In this article we present the available data on drug-eluting technology.

\section{Keywords}

Paclitaxel, drug-eluting technology, peripheral arterial disease, sirolimus, drug-coated balloon, drug-eluting stents

Disclosures: Leonardo Marques, Silke Hopf-Jensen, Michael Preiss and Stefan Mueller-Huelsbeck have no financial or non-financial relationships or activities to declare in relation to this article.

Review process: Double-blind peer review.

Compliance with ethics: This study involves a review of the literature and did not involve any studies with human or animal subjects performed by any of the authors.

Data availability: Data sharing is not applicable to this article as no datasets were generated or analysed during the writing of this article.

Authorship: All named authors meet the criteria of the International Committee of Medical Journal Editors

for authorship for this manuscript, take responsibility for the integrity of the work as a whole and have given final approval for the version to be published.

Access: This article is freely accessible at touchCARDIO.com (C) Touch Medical Media 2021

Received: 11 January 2021

Accepted: 3 June 2021

Published online: 10 December 2021

Citation: Heart International. 2021;15(2):73-8

Corresponding Author: Leonardo Marques,

Department of diagnostic and interventional Radiology/

Neuroradiology, Diako Hospital, Knuthstrasse 1, 24939

Flensburg, Germany. E: marquesle@diako.de

Support: No funding was received in

the publication of this article.
Drug-eluting technology is a widely accepted, proven treatment for coronary artery stenosis and occlusions, with superior results when compared with bare metal stents or plain old balloon angioplasty (POBA). ${ }^{1,2}$ Many studies also proved drug-eluting stents (DES) and drug-coated balloons (DCB) to be superior to POBA when treating lower limb arteries. ${ }^{3,4}$

Paclitaxel is a cytostatic chemotherapy drug belonging to the taxane group, and is a commonly used systemic treatment for several carcinomas, including lung, breast and prostate. When treating peripheral arterial disease, some current devices contain paclitaxel to prevent restenosis. ${ }^{5}$ The drug is applied directly to the vessel wall, where it acts locally to prevent over-response and cell proliferation (intimal hyperplasia) triggered after an injury to the vessel wall, such as stretching in balloon angioplasty and/or stent deployment.

After more than a decade on the market, the reputation, and therefore use, of DES and DCB containing paclitaxel for peripheral arterial disease suffered a massive setback when, in December 2018, a meta-analysis of 28 randomized controlled trials with 4,663 patients showed an increase in all-cause death in patients receiving paclitaxel, compared with control groups. Katsanos et al. reported a significant increase in all-cause death at 2 years with paclitaxel versus controls (7.2\% versus $3.8 \%$ crude risk of death, respectively; risk ratio, 1.68; 95\% confidence interval [CI], 1.15-2.47; number-needed-to-harm, 29 patients [95\% Cl, 19-59]). All-cause death up to 5 years (three randomized controlled trials with 863 cases) further increased with paclitaxel versus controls (14.7\% versus $8.1 \%$ crude risk of death, respectively; risk ratio, 1.93; 95\% Cl, 1.27-2.93; number-needed-to-harm, 14 patients [95\% $\mathrm{Cl}, 9-32]){ }^{6}$

Following this publication, interventionalists and healthcare officials attempted to explain this phenomenon and debated how to fill the gap left by this relevant therapy until further studies were completed to prove or disprove the conclusions. As a result, the indication for paclitaxel-eluting devices has narrowed; it is now mostly restricted to lesions with high risk of restenosis, such as in-stent stenosis..$^{7.8}$ Physicians are instructed to weigh up the risks and benefits of using paclitaxel-eluting devices, and to fully convey risks to the patient within a well-informed, balanced and documented informed consent process.

While waiting for some long-term data on paclitaxel to be published, the focus has slowly shifted to some promising, mainly limus-based drugs, such as sirolimus. In this article, we briefly summarize available evidence on drug-eluting technology for treating peripheral arterial disease.

The focus of the studies included in this article was to evaluate the treatment with DCBS on symptomatic patients with a Rutherford score of 2 or higher. Some studies also focused on comparing devices directly. All trials discussed studied patients with claudication. Endpoints were usually primary patency, as assessed via ultrasound, and freedom from target lesion revascularization. Specific lesion characteristics, such as length and severity, vary between the 
studies, although the lesions were mainly located on the superficial femoral artery or the upper popliteal artery.

\section{IN.PACT SFA randomized trial}

The IN.PACT SFA trial (Randomized Trial of IN.PACT Admiral $®$ Drug Coated Balloon vs Standard PTA for the Treatment of SFA and Proximal Popliteal Arterial Disease; ClinicalTrials.gov identifier: NCT01175850) enrolled 331 patients with intermittent claudication or ischaemic rest pain attributable to SFA and PPA disease, randomized in a 2:1 ratio for treatment either with the paclitaxel-coated IN.PACT Admiral DCB (Medtronic, Dublin, Ireland) or standard percutaneous transluminal angioplasty (PTA) of the SFA and/or PPA. Mean lesion length and the percentage of total occlusions for the DCB and PTA arms were $8.94 \pm 4.89$ and $8.81 \pm 5.12 \mathrm{~cm}(\mathrm{p}=0.82)$ and $25.8 \%$ and $19.5 \%(p=0.22)$, respectively. ${ }^{14}$

Three-year data showed a higher patency and freedom from target lesion revascularization rate for the DCB group, namely $69.5 \%$ patency for DCB versus $45.1 \%$ for the POBA, and $84.8 \%$ freedom from target lesion revascularization for the DCB versus $68.9 \%$ for the POBA. The authors claim there were no device- or procedure-related deaths, adjudicated by an independent Clinical Events Committee..$^{15}$

Authors from the IN.PACT trial analysed two single-arm and two randomized trials of paclitaxel-coated balloons, with 1,837 patients, for all-cause mortality. The results after stratification showed no correlation between exposure to different doses of paclitaxel and mortality. In addition, when comparing with POBA, no statistically significant increase in mortality was detected $(p=0.092){ }^{16}$

\section{COMPARE and RANGER II SFA trials}

The COMPARE trial (ClinicalTrials.gov identifier: NCT02701543) compared two DCBS: the RangerTM DCB (Hemoteq, Würselen, Germany) and the IN.PACT'M AdmiralTM DCB or IN.PACT Pacific ${ }^{\mathrm{TM}}$ DCB (Medtronic vascular, Santa Clara, CA, USA), ${ }^{9,10}$ This trial compared devices in a 1:1 ratio in 414 patients with peripheral arterial disease. The primary aim of the trial was to prove that the low-dose Ranger DCB is non-inferior to the higher dose IN.PACT Admiral/Pacific DCB. The Ranger DCB is a paclitaxel-coated balloon with a drug density of $2 \mu \mathrm{g} / \mathrm{mm}^{2}$, whereas the IN.PACT Admiral/Pacific DCBs have a drug density of $3.5 \mu \mathrm{g} / \mathrm{mm}^{2}{ }^{20}$

Twelve-month results were published in July 2020, concluding that the Ranger DCB is non-inferior to the IN.PACT Admiral/Pacific DCBS, with a 1-year event-free survival of $88.4 \%$ for the Ranger DCB versus $89.4 \%$ for the IN.PACT DCBS. ${ }^{10}$ Bailout stenting rates were $25-30 \%$ for both groups, mainly when treating longer $(>20 \mathrm{~cm}$ ) lesions. This ongoing study will follow patients for up to 2 years for patency and up to 5 years for target lesion revascularization. ${ }^{10}$

The Ranger II SFA trial (RANGERTM Paclitaxel Coated Balloon vs Standard Balloon Angioplasty; ClinicalTrials.gov identifier: NCT03064126) is ongoing. ${ }^{11}$ The preliminary 12-month follow-up results of 376 symptomatic (Rutherford 2-4) patients presenting stenosis up to $180 \mathrm{~mm}$ long and/or occlusions up to $100 \mathrm{~mm}$ presented a freedom from target lesion revascularization rate of $94.5 \%$ for the Ranger DCB and 83.5\% for the standard, uncoated balloon (3:1 randomization). ${ }^{12}$ These results are in line with previous studies involving the Ranger $D C B .{ }^{13}$

\section{ILLUMENATE trials}

The ILLUMENATE EU (CVI Drug Coated Balloon European Randomized Clinical Trial; ClinicalTrials.gov identifier: NCT01858363) and ILLUMENATE Pivotal (Pivotal Trial of a Novel Paclitaxel-Coated Percutaneous
Angioplasty Balloon; ClinicalTrials.gov identifier: NCT01858428) randomized controlled trials together included 594 ( $n=294$ ILLUMENATE EU, $n=300$ ILLUMENATE Pivotal) patients (Rutherford class 2-4) who received either the low-dose, paclitaxel-coated Stellarex DCB (Spectranetics Corp., Colorado Springs, CO, USA) or POBA in a 3:1 ratio. Mean lesion length in the ILLUMENATE EU was $72 \mathrm{~mm}$ and $71 \mathrm{~mm}$, and $19.2 \%$ and $19.0 \%$ of lesions represented total occlusions, respectively. In the ILLUMENATE Pivotal, baseline characteristics were similar between groups, the mean lesion length was $83 \mathrm{~mm}$, and $44.0 \%$ were severely calcified. ${ }^{17,18}$

In the ILLUMENATE EU trial, the primary patency at 2 years was higher in the DCB group than the POBA group (75.9\% versus $61.0 \%$, respectively; $\mathrm{P}=0.025)$, and the rate of clinically driven target lesion revascularization (CD-TLR) was significantly lower in the DCB group than the POBA group (12.1\% versus $30.5 \%$, respectively; $P<0.001) .^{17}$ There were no $\operatorname{limb}$ amputations in either group, and all-cause mortality was similar between groups (6.5\% DCB versus 5.1\% POBA; $p=1.00) .{ }^{19}$

In the ILLUMENATE Pivotal Study, the primary patency rate was significantly higher with DCB $(76.3 \%$ for DCB versus $57.6 \%$ for PTA, $\mathrm{P}=0.003)$. Primary patency per Kaplan-Meier estimates at day 365 was $82.3 \%$ for DCB versus $70.9 \%$ for PTA ( $P=0.002)$. The rate of clinically driven target lesion revascularization was significantly lower in the DCB cohort (7.9\% versus $16.8 \%, \mathrm{P}=0.023)$. Improvements in ankle-brachial index, Rutherford class, and quality of life were comparable, but the PTA cohort required twice as many revascularizations. ${ }^{18}$

The 5-year data presented at the Leipzig Interventional Course 2021 (LINC, 25-29th January 2021, online) demonstrated no statistical difference in the mortality; the ILLUMENATE EU trial showed $19.3 \%$ mortality in the DCB group versus $19.4 \%$ in the POBA group, and the ILLUMENATE Pivotal randomized controlled trial showed $21.2 \%$ mortality in the DCB group versus $20.2 \%$ in the POBA group..$^{20}$

\section{SELUTION SFA trial}

The SELUTION SLRTM DCB (M.A. Med Alliance SA, Nyon, Switzerland) is a sirolimus-eluting balloon. Of the 50 patients with symptomatic moderate-to-severe lower limb ischaemia (Rutherford categories 2 or 3) enrolled on the SELUTION SFA trial (ClinicalTrials.gov identifier: NCT02941224) between October 2016 and May 2017 to four centres in Germany; 42 patients completed the 24-month follow-up.21

The primary trial objective was comparison of angiographic late lumen loss at 6 months against an objective performance criterion (OPC) value of $1.04 \mathrm{~mm}$ for uncoated balloon angioplasty. Secondary endpoints included device, procedural, and clinical success; clinical and imaging assessments of primary patency and restenosis; functional assessments including Rutherford category and ankle-brachial index (ABI); and major adverse events (composite of cardiovascular mortality, index limb amputation, target limb thrombosis and clinically-driven target lesion revascularization [CD-TLR]).

The currently available published data is on the 6-month outcome. The rate of primary patency by duplex ultrasound was $88.4 \%$, and freedom from angiographic binary restenosis was $91.2 \%$. Through 6 months, there was significant improvement over baseline in Rutherford categories $(p<0.001)$ and in $A B I$ measurements $(p<0.001)$. A single case $(2.0 \%)$ of CD-TLR occurred at 5 months. There were no other major adverse events. ${ }^{22}$ According to the presentation held at the 2019 Vascular Interventional Advances (VIVA) Annual Conference in Las Vegas, the 
freedom from target lesion revascularization rate was $87.5 \%$ after 1 year, and all-cause mortality was $0.0 \%{ }^{23}$

\section{Drug-eluting stents}

Long and complex lesions with balloon angioplasty alone are prone to increased rates of flow-limiting dissection and recoil, with higher incidence of restenosis and re-occlusions in the years following the index procedure. ${ }^{24}$ Bailout or primary stenting of these types of lesions have been consistently proven more effective. 25,26

Many studies and meta-analyses have shown that using DES results in decreased rates of restenosis and target lesion revascularization when compared with bare metal stents. For instance, studies on the paclitaxel-coated Zilver ${ }^{\circledR}$ PTX ${ }^{\circledR}$ drug-eluting peripheral stent (Cook Medical, Bloomington, IN, USA) presented promising results, even for patients with Trans-Atlantic Inter-Society Consensus Document II (TASC II) type C or D lesions, which produce worse patient outcomes. ${ }^{27}$

Early studies with stents coated with drugs other than paclitaxel have, in turn, failed to provide good results. The 2006 SIROCCO trial (A Study of the SMART Stent in the Treatment SFA Disease; ClinicalTrials.gov identifier: NCT00232869) showed similar results between the sirolimus-eluting S.M.A.R.T. ${ }^{\oplus}$ Vascular Stent (Cordis Corporation, Miami Lakes, FL, USA) and the uncoated version of the stent. ${ }^{28}$ After 24 months, the restenosis rate in the sirolimus group was $22.9 \%$ versus $21.1 \%$ in the bare metal stent group $(p>0.05)$. Although these results were as expected, the trial showed no relevant benefits of DES over the bare metal stent..$^{29}$

The single-arm, non-randomized STRIDES trial (A Safety and Efficacy Study of the Dynalink ${ }^{\circledR}$-E Everolimus Eluting Peripheral Stent System; ClinicalTrials.gov identifier: NCT00475566; 2011), with 104 participants, analysed an everolimus-eluting, self-expanding nitinol stent. ${ }^{30}$ The results suggested improved primary patency at 6 months, although this improvement was not sustained at 12 months. ${ }^{31}$

\section{Zilver PTX trials}

The Zilver PTX stent consists of a self-expanding nitinol stent with a polymer-free, paclitaxel coating. It was among the first paclitaxel-eluting stents approved and marketed (first FDA submission 2001, CE mark approval 2009). ${ }^{32,33}$

The initial analysis of the Zilver PTX stent was divided into two trials. The first was a randomized trial (ClinicalTrials.gov identifier: NCT00120406) comparing the Zilver PTX stent with a control group consisting of PTA and, should a bailout stent be required, a possible second randomization between a plain bare metal stent and the Zilver PTX stent. ${ }^{34,35}$ The second trial was single arm, designed to test the stent on a real-world scenario, with no limits on the length of the lesions and the underlying reason for stenting, including in-stent restenosis. ${ }^{36}$

The randomized trial enrolled patients with symptomatic femoropopliteal artery disease (Rutherford category 2-6); approximately $91.0 \%$ had claudication; $9.0 \%$ had critical limb ischaemia. ${ }^{35}$ Patients were randomly assigned to DES $(n=236)$ or PTA $(n=238)$ groups. Patients experiencing acute PTA failure underwent secondary randomization to provisional bare metal stent $(n=59)$ or DES $(n=61)$. The maximal lesion length was $70 \mathrm{~mm}$ in the first phase and $140 \mathrm{~mm}$ in the second phase of this trial. The mean lesion length was $54 \pm 41 \mathrm{~mm}$ for the Zilver PTX stent group and $53 \pm 40 \mathrm{~mm}$ for the control group. Occlusions were found in $30.0 \%$ and $25.0 \%$ of the patients in the DES and control groups, respectively. In total, 546 stents were implanted; 453 were Zilver PTX stents and 93 were plain bare metal stents. The primary patency at 5 years was $66.4 \%$ for the DES group and $43.4 \%$ in the control group. Freedom from target Iesion vascularization was $83.1 \%$ versus $67.6 \%$ in the DES and control groups, respectively, again favouring the DES over the control group. Worth noting is the higher 5 -year all-cause mortality rate of $16.9 \%$ for the DES group versus $10.2 \%$ for the control group $(p=0.03){ }^{34}$

The single-arm study enrolled 787 patients (Rutherford category 2-6) undergoing DES treatment. A total of 900 lesions (24.3\% restenotic lesions, of which $59.4 \%$ were in-stent stenoses) were treated with 1,722 Zilver PTX stents; the mean lesion length was $99.5 \pm 82.1 \mathrm{~mm}$. The 12-month data included an $89.0 \%$ event-free survival rate, an $86.2 \%$ primary patency rate and a $90.5 \%$ rate of freedom from target lesion revascularization. ${ }^{36}$

\section{IMPERIAL trial}

Following the initial MAJESTIC trial (ClinicalTrials.gov identifier: NCT01820637) on Boston Scientific's EluviaTM drug-eluting vascular stent system (paclitaxel, polymer-coated; Boston Scientific, Maple Grove, MN, USA), which presented a freedom from target lesion revascularization of $85.3 \%$ at 3 -year follow-up (index $n=57$ ), the IMPERIAL trial (ClinicalTrials.gov identifier: NCT02574481) compared the Eluvia stent with the Zilver PTX stent. ${ }^{37-39}$

In this single-blind, non-inferiority study, 465 patients were randomly assigned 2:1 to receive treatment with the Eluvia stent $(n=309)$ or Zilver PTX stent $(n=156)$. The primary efficacy endpoint was primary patency, defined as a peak systolic velocity ratio $\leq 2.4$ on Doppler ultrasound, without CD-TLR or bypass of the target lesion. Lesions up to $140 \mathrm{~mm}$ in length could be treated. The Long Lesion Substudy enrolled patients with lesions $>140 \mathrm{~mm}$ and $\leq 190 \mathrm{~mm}$ in length. ${ }^{40}$

At 12 months, non-inferiority was declared, with a primary patency of 86.8\% ( $\mathrm{n} / \mathrm{N}=231 / 266)$ in the Eluvia stent group and $81.5 \%(\mathrm{n} / \mathrm{N}=106 / 130)$ in the Zilver PTX stent group. These data were later corrected to $92.1 \%$ primary patency for the Eluvia stent and $81.8 \%$ for the Zilver PTX stent. Freedom from target lesion revascularization was $95.5 \%$ for the Eluvia stent group and $91.0 \%$ for the Zilver PTX stent group (target lesion revascularization $n=13$ each, $p=0.067$ ). No deaths were reported in either group by the first year. ${ }^{40}$

The 2-year results were presented at LINC 2020, where freedom from target lesion revascularization was $86.5 \%$ in the Eluvia stent group (target lesion revascularization $\mathrm{n} / \mathrm{N}=37 / 275,13.5 \%$ ) versus $79.9 \%$ in the Zilver PTX stent group (CD-TLR $n / \mathrm{N}=27 / 134,20.1 \%, \mathrm{p}=0.0495){ }^{37}$

For an overview on other relevant trials, please refer to Figure 1.11,14,17,18,34-60

\section{Other indications for use}

\section{Arteriovenous dialysis fistulae}

Treatment of arteriovenous dialysis fistulae is challenging, as it commonly requires frequent interventions due to restenosis. Drug-eluting technologies help improve long-term results; nevertheless, it is worth noting that patients receiving dialysis tend to undergo multiple sessions of angioplasty of the arteriovenous fistulae, thus also potentially exposing these patients to larger doses of the drug eluted by the device at other organs, such as lungs. ${ }^{61}$ 
Figure 1: Results from several studies on clinically driven target lesion revascularization and mean lesion length at 12 months $11,14,17,1,34,60$

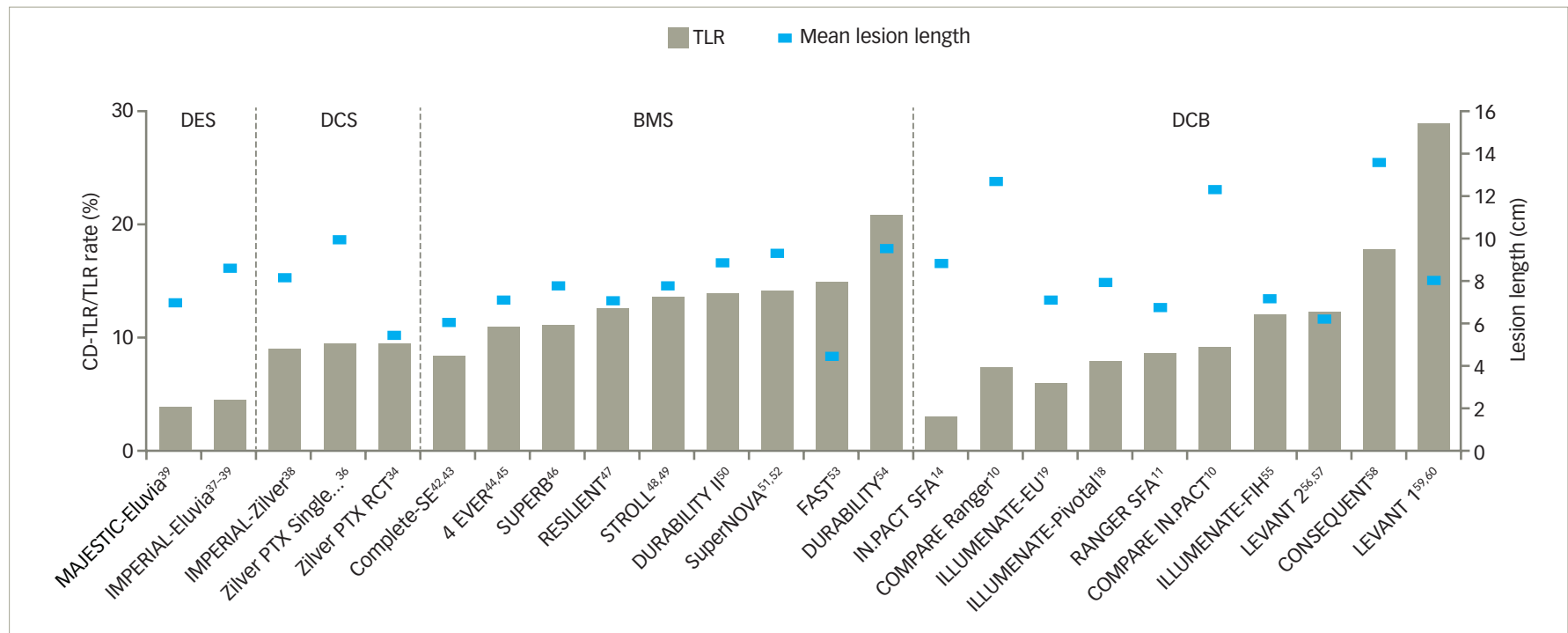

$B M S=$ bare metal stent; $C D$-TLR = clinically driven target lesion revascularization; $D C B=$ drug-coated balloon; $D C S=$ drug-Coated stent; $D E S=d r u g$-eluting stent; $T L R=$ target lesion revascularization.

The LUTONIX AV (Study Comparing Lutonix AV Drug Coated Balloon vs Standard Balloon for Treatment of Dysfunctional AV Fistulae; ClinicalTrials.gov identifier: NCT02440022) was a randomized controlled trial in which 285 patients with arteriovenous fistula were randomized to receive either the LUTONIX ${ }^{\circledR} 035$ DCB (Becton Dickinson, Maple Grove, MN, USA) or POBA. ${ }^{62}$ Target lesion primary patency at 180 days was $71.4 \%$ in the DCB group and $63.0 \%$ in the POBA group ( $p=0.0562$ ). Statistical significance was not achieved, nevertheless, the overall results demonstrated a potential trend towards higher patency rates in the DCB group through 12 months. All-cause mortality at 12 months was $12.8 \%$ for the DCB group and $9.7 \%$ for the POBA group. ${ }^{63}$

\section{Below the knee}

Patients with critical limb ischaemia (CLI) typically have comorbidities, and are at increased risk of amputation and death compared with the normal population. Mortality is $20.0 \%$ at 6 months after diagnosis, and $50.0 \%$ at 5 years. ${ }^{64}$

The MERLION trial (Investigating the Safety and Efficacy of the Treatment With Luminor DCB and Angiolite DES of iVascular in TASC C and D Tibial Occlusive Disease in Patients With Critical Limb Ischemia; ClinicalTrials.gov identifier: NCT04073121) compared the Luminor DCB and Angiolite DES (both iVascular, Barcelona, Spain) in below-the-knee treatment of 50 patients with critical limb ischaemia (66 lesions). ${ }^{65}$ Data presented at LINC 2021 showed a freedom from target lesion revascularization of $82.0 \%$, an amputation-free survival of $74.0 \%$ and primary patency of $69.0 \%$ after the first year. No deaths within 30 days of the procedure were reported. ${ }^{66}$

In the AcoArt II-BTK trial (ClinicalTrials.gov identifier: NCT02137577), 120 patients with $\mathrm{CLI}$ and infrapopliteal lesions received the Litos \& Tulip ${ }^{\circledast}$ DCB (Acotec Scientific, Beijing, China) or the uncoated balloon ( $n=61$ in the DCB group, $n=59$ in the POBA group). ${ }^{67}$ Freedom from CD-TLR at 12 months was seen in $91.5 \%$ of patients in the DCB group and $76.8 \%$ in the control group. No statistically significant difference in mortality (1.7\% in DCB group versus $3.6 \%$ in control group; $\mathrm{p}=0.53$ ) was detected up to 1 year.68

\section{Discussion}

Drug-eluting technology is a superior therapy for the treatment of peripheral arterial disease, when compared with uncoated balloon angioplasty. It has decreased the need for re-interventions by ensuring higher patency rates on a longer term. This has arguably helped to reduce costs (both for patients and hospitals, depending on location) and improve quality of life in patients with peripheral arterial disease.

Since the publication of a meta-analysis by Katsanos et al. in 2018 that showed higher pooled mortality rates in groups receiving paclitaxel-coated devices, healthcare agencies and societies have reviewed their guidelines on using such devices. ${ }^{5-8}$ As such, use of these devices has dramatically reduced, prompting research into drug-free devices.

To date, a definite dose-effect correlation between paclitaxel and mortality has not been established. The mortality signal has been inconsistent across several studies.

Recent follow-up data for long-term trials, such as the IN.PACT and ILLUMENATE randomized control trials, have also shown similar mortality rates between the DCB and POBA groups. ${ }^{14,15,17-19}$ An analysis of over 9 million claims from a German health insurance provider $(64,771$ patients, 107,112 procedures with 23,137 drug-eluting devices) could not find any association between increased mortality and the usage of paclitaxel-coated devices. Interestingly, DCB was associated with decreased mortality in the year following the procedure, with no notable difference in the years thereafter. ${ }^{69}$

New trials are focusing on substituting paclitaxel with alternative drugs, such as sirolimus. ${ }^{22}$ Nevertheless, the lack of consistent, positive data on these sirolimus-coated devices in previous studies still limits their application. 
Currently, regulatory agencies and societies recommend that, until the increased mortality of patients who received paclitaxel-coated devices can be clarified, their use in clinical practice should be carefully evaluated and explicit patient consent should be obtained. ${ }^{7.8}$

It is the opinion of the authors of this article that the lack of both a drug dose-mortality relation and a causal explanation for the mortality risk defines an area requiring further investigation. Future endovascular device trial designs should incorporate strategies and methods to maximize patient retention and facilitate long-term assessment and reporting of vital statistics.

Paclitaxel-coated devices provide important benefits when used for endovascular therapy, especially in terms of restenosis and revascularization prevention, but may possibly increase fatality. To date, we continue to believe that the benefits outweigh the risks for use of these devices in selected patients who are at high risk for restenosis as determined by their treating physicians. $\square$
1. Moses J, Leon M, Popma J, et al. Sirolimus-eluting stents versus standard stents in patients with stenosis in a native coronary artery. N Eng/ J Med. 2003;349:1315-23.

2. Piccolo $\mathrm{R}$, Bonaa $\mathrm{K}$, Efthimiou $\mathrm{O}$, et al. Drug-eluting or bare-metal stents for percutaneous coronary intervention: a systematic review and individual patient data meta-analysis of randomised clinical trials. Lancet. 2019:393:2503-10.

3. Baerlocher MO, Kennedy SA, Rajebi MR, et al. Meta-analysis of drug-eluting balloon angioplasty and drug-eluting stent placement for infrainguinal peripheral arterial disease. J Vasc Interv Radiol. 2015;26:459-73.

4. Zeller T, Baumgartner I, Scheinert D, et al. Drug-eluting balloon versus standard balloon angioplasty for infrapopliteal arterial revascularization in critical limb ischemia: 12 -month results from the IN.PACT DEEP randomized trial. J Am Coll Cardiol. 2014;64:1568-76

5. Klumb C, Lehmann T, Aschenbach R, et al. Benefit and risk from paclitaxel-coated balloon angioplasty for the treatment of femoropopliteal artery disease: a systematic review and meta-analysis of randomised controlled trials. EClinicalMedicine. 2019:16:42-50.

6. Katsanos K, Spiliopoulos S, Kitrou P, et al. Risk of death following application of paclitaxel-coated balloons and stents in the femoropopliteal artery of the leg: a systematic review and meta-analysis of randomized controlled trials. J Am Heart AsSoc. 2018:7:e011245

7. Cardiovascular and Interventional Radiological Society of Europe. Updated CIRSE Position on the use of paclitaxel-coated balloons and stents in PAD. 2019. Available at: Www.radiologen. $\mathrm{nl} /$ sites/default/files/nieuws/cirse_position_statement.pd (accessed 5 July 2021).

8. US Food and Drug Administration. UPDATE: Treatment of peripheral arterial disease with paclitaxel-coated balloons and paclitaxel-eluting stents potentially associated with increased mortality. 2019. Available at: www.fda.gov/medical-devices/ letters-health-care-providers/August-7-2019-update-treatmentperipheral-arterial-disease-paclitaxel-coated-balloons-andpaclitaxel (accessed 4 July 2021).

9. ClinicalTrials gov. Compare I Pilot Study for the Treatment of subjects With Symptomatic Femoropopliteal Artery Disease. ClinicalTrials.gov Identifier: NCT02701543. Available at: www.clinicaltrials.gov/ct2/show/NCT02701543 (accessed 25 June 2021).

10. Steiner S, Schmidt A, Zeller T, et al. COMPARE: prospective, randomized, non-inferiority trial of high- vs. low-dose paclitaxe drug-coated balloons for femoropopliteal interventions. Eur Heart J. 2020;41:2541-52.

11. ClinicalTrials.gov. RANGER TM Paclitaxel Coated Balloon vs Standard Balloon Angioplasty (RANGER II SFA). ClinicalTrials.gov Identifier: NCT03064126. Available at: https://clinicaltrials.gov/ ct2/show/NCT03064126 (accessed 25 June 2021).

12. Boston Scientific. RANGER II SFA Pivotal Trial. Available at: www.bostonscientific.com/en-EU/medical-specialties/vascularsurgery/drug-eluting-therapies/ranger/ranger-II-sfa-pivotal-trial. $\mathrm{html}$ (accessed 9 December 2021)

13. Steiner $\mathrm{S}$, Willfort-Ehringer $A$, Sievert $H$, et al. 12-month results from the first-in-human randomized study of the Ranger paclitaxel-coated balloon for femoropopliteal treatment JACC Cardiovasc Interv. 2018;11:934-41.

14. ClinicalTrials.gov. Randomized Trial of IN.PACT Admiral ${ }^{\circledR}$ Drug Coated Balloon vs Standard PTA for the Treatment of SFA and Proximal Popliteal Arterial Disease (INPACT SFA I). ClinicalTrials.gov Identifier: NCT01175850. Available at: https://clinicaltrials.gov/ct2/show/NCT01175850 (accessed 25 June 2021).

15. Schneider PA, Laird JR, Tepe G, et al. Treatment effect of drug-coated balloons is durable to 3 years in the femoropopliteal arteries: long-term results of the IN.PACT SFA randomized trial. Circ Cardiovasc Interv. 2018:11:e005891.

16. Schneider PA, Laird JR, Doros G, et al. Mortality not correlated with paclitaxel exposure: an independent patient-level meta-analysis of a drug-coated balloon. J Am Coll Cardio 2019;73:2550-63.

17. ClinicalTrials.gov. CVI Drug Coated Balloon European Randomized Clinical Trial. ClinicalTrials.gov Identifier: NCT01858363. Available at: https://clinicaltrials.gov/ct2/show/ NCT01858363 (accessed 25 June 2021).

18. ClinicalTrials.gov. Pivotal Trial of a Novel Paclitaxel-Coated Percutaneous Angioplasty Balloon (ILLUMENATE). ClinicalTrials. gov Identifier: NCT01858428. Available at: https://clinicaltrials. gov/ct2/show/NCT01858428 (accessed 25 June 2021).

19. Brodmann M, Werner M, Meyer D-R, et al. Sustainable antirestenosis effect with a low-dose drug-coated balloon: the antirestenosis effect with a low-dose drug-coated balloon: the
ILLUMENATE European randomized clinical trial 2-year results.
ACC Cardiovasc Interv. 2018;11:2357-63

20. Brodmann M. Final Long-Term Mortality Results of Paclitaxel-Coated DCBS from the ILLUMENATE RCTs: 5-Yea Data from EU RCT and Pivotal studies. Presented at Leipzig Interventional Course (LINC), Leipzig, Germany, 25-29 Interventional Course (LINC), Leipzig, Germany, 25-29 media/1325BrodmannMarianne.pdf (accessed 8 December media/

21. ClinicalTrials.gov. First-in-human Evaluation of the SELUTION DCB, a Novel Sirolimus Coated Balloon in Peripheral Arteries. ClinicalTrials.gov Identifier: NCT02941224. Available at: https://clinicaltrials.gov/ct2/show/NCT02941224 (accessed 7 December 2021).

22. Zeller T. A novel sustained limus release eluting balloon: 2-year data from the SELUTION SFA trial. Presented at Vascular Interventional Advances (VIVA) Annual Conference, Las Vegas, NV, USA, 4-7 November 2019

23. Zeller T, Brechtel K, Meyer D-R, et al. Six-month outcomes from the first-in-human, single-arm SELUTION sustained-limusrelease drug-eluting balloon trial in femoropopliteal lesions. J Endovasc Ther. 2020:27:683-90.

24. Schillinger M, Sabeti S, Loewe $C$, et al. Balloon angioplasty versus implantation of nitinol stents in the superficial femoral artery. N Eng/ J Med. 2006;354:1879-88.

25. Schulte KL, Kralj I, Gissler HM, et al. MISAGO 2: one-year outcomes after implantation of the Misago self-expanding nitinol stent in the superficial femoral and popliteal arteries of 744 patients. J Endovasc Ther. 2012;19:774-84.

26. Kasapis C, Henke PK, Chetcuti SJ, et al. Routine stent implantation vs. percutaneous transluminal angioplasty in femoropopliteal artery disease: a meta-analysis of randomized controlled trials. Eur Heart J. 2009;30:44-55.

27. Bosiers M, Peeters P, Tessarek J, et al. The Zilver ${ }^{\oplus}$ PTX $X^{\circledR}$ single arm study: 12-month results from the TASC C/D lesion subgroup. I Cardiovasc Surg (Torino). 2013;54:115-22.

28. ClinicalTrials.gov. A Study of the SMART Stent in the Treatment SFA Disease. (SIROCCO). ClinicalTrials.gov Identifier NCT00232869 Available at: https://clinicaltrials.sov/ct2/show/ NCT00232869 (accessed 25 June 2021).

29. Duda SH, Bosiers M, Lammer I, et al. Drug-eluting and bare nitinol stents for the treatment of atherosclerotic lesions in the superficial femoral artery: long-term results from the SIROCCO trial. J Endovasc Ther. 2006;13:701-10.

30. ClinicalTrials.gov. A Safety and Efficacy Study of the Dynalink $\otimes-E$ Everolimus Eluting Peripheral Stent System (STRIDES). ClinicalTrials.gov Identifier: NCT00475566. Available at: www.clinicaltrials.gov/ct2/show/NCT00475566 (accessed 25 June 2021)

31. Lammer J, Bosiers $\mathrm{M}$, Zeller T, et al. First clinical trial of nitinol self-expanding everolimus-eluting stent implantation for peripheral arterial occlusive disease. J Vasc surg. 2011:54:394-401.

32. Cook Medical. Cook Medical's Zilver(R) PTX(R) earns FDA approval as first drug-eluting stent in U.S. to treat periphera arterial disease 2012 Available at: wuw cookmedical.com/ newsroom/cook-medicals-zilver-ptx-earns-fda-approval-asfirst-drug-eluting-stent-in-u-s-to-treat-peripheral-arterialdisease/\#: : :text=\%E2\%80\%94\%20Cook\%20Medical\%20has\%20 received\%20U.S. blockages\%20in\%20a\%20peripheral\%20artery. (accessed 8 December 2021).

33. Vascular News. Zilver PTX stent from Cook Medical gains CE mark. 2009. Available at: https://vascularnews.com/zilverptx-stent-from-cook-medical-gains-ce-mark/ (accessed 8 December 2021).

34. Dake MD, Ansel GM, Jaff MR, et al. Durable clinical effectiveness with paclitaxel-eluting stents in the femoropopliteal artery: 5 -year results of the Zilver PTX randomized trial. Circulation. 2016;133:1472-83.

35. ClinicalTrials.gov. Evaluation of the Zilver PTX Drug-Eluting Stent in the Above-the-Knee Femoropopliteal Artery (Zilver PTX). ClinicalTrials.gov Identifier: NCT00120406. Available at: https://clinicaltrials.gov/ct2/show/NCT00120406 (accessed 7 December 2021).

36. Dake MD, Scheinert D, Tepe G, et al. Nitinol stents with polymer-free paclitaxel coating for lesions in the superficia femoral and popliteal arteries above the knee: twelve-month safety and effectiveness results from the Zilver PTX single-arm clinical study. J Endovasc Ther. 2011:18:613-23.

37. ClinicalTrials.gov. Stenting of the Superficial Femoral and/or Proximal Popliteal Artery Project (MAJESTIC). ClinicalTrials.gov Identifier: NCT01820637. Available at: https://clinicaltrials.gov/ ct2/show/NCT01820637 (accessed 25 June 2021).

38. ClinicalTrials.gov. ELUVIA ${ }^{\text {TM }}$ Drug-eluting Stent Versus Zilver ${ }^{\oplus}$ PTX ${ }^{\circledast}$ Stent (IMPERIAL). ClinicalTrials.gov Identifier:
NCT02574481. Available at: https://clinicaltrials.gov/ct2/show/ NCT02574481 (accessed 25 June 2021).

39. Müller-Hülsbeck S, Keirse K, Zeller T, et al. Long-term results from the MAJESTIC trial of the Eluvia paclitaxel-eluting stent for femoropopliteal treatment: 3 -year follow-up. Cardiovaso Intervent Radiol. 2017;40:1832-8.

40. Gray WA, Keirse K, Soga Y, et al. A polymer-coated, paclitaxel-eluting stent (Eluvia) versus a polymer-free paclitaxel-coated stent (Zilver PTX) for endovascular femoropopliteal intervention (IMPERIAL): a randomised, non-inferiority trial. Lancet. 2018;392:1541-51.

41. Gray WA. 2-year outcomes from the IMPERIAL randomized study of Eluvia and Zilver PTX. Presented at Leipzig Interventional Course (LINC), Leipzig, Germany, 28-31 January 2020.

42. Laird JR, Jain A, Zeller T, et al. Nitinol stent implantation in the superficial femoral artery and proximal popliteal artery: twelve-month results from the Complete SE multicenter tria. J Endovasc Ther. 2014;21:202-12.

43. ClinicalTrials.gov. The Complete $₫$ SE SFA study for the treatment of SFA/PPA lesions. ClinicalTrials.gov Identifier: NCT00814970. Available at: https://clinicaltrials.gov/ct2/show/ NCT00814970 (accessed 5 July 2021).

44. Bosiers M, Deloose K, Callaert J, et al. 4-French-compatible endovascular material is safe and effective in the treatment of femoropopliteal occlusive disease: Results of the 4-EVER trial. J Endovasc Ther. 2013;20:746-56.

45. ClinicalTrials.gov. 4-EVER : A trial investigating the safety of $4 \mathrm{~F}$ endovascular treatment of infra-inguinal arterial stenotic disease (4-EVER). ClinicalTrials.gov Identifier: NCT01413139. Available at: https://clinicaltrials.gov/ct2/show/NCT01413139 (accessed 5 July 2021).

46. Garcia LA, Rosenfield KR, Metzger CD, et al. SUPERB final 3-year outcomes using interwoven nitinol biomimetic supera stent. Catheter Cardiovasc Interv. 2017;89:1259-67.

47. Laird JR, Katzen BT, Scheinert D, et al. Nitinol stent implantation versus balloon angioplasty for lesions in the superficial femora artery and proximal popliteal artery: twelve-month results from the RESILIENT randomized trial. Circ Cardiovasc Intery. 2010;3:267-76

48. Bunte MC, Cohen DJ, Jaff MR, et al. Long-term clinical and quality of life outcomes after stenting of femoropopliteal arter stenosis: 3-year results from the STROLL study. Catheter Cardiovasc Interv. 2018:92:106-14.

49. ClinicalTrials.gov. S.M.A.R.T.® nitinol self-expandable stent in the treatment of obstructive superficial femoral artery disease (STROLL). ClinicalTrials.gov Identifier: NCT00739102. Available at: https://clinicaltrials.gov/ct2/show/NCT00739102 (accessed 5 July 2021).

50. Matsumura JS, Yamanouchi D, Goldstein JA, et al. The United States study for evaluating endovascular treatments of lesions in the superficial femoral artery and proximal popliteal by using the Protégé Everflex Nitinol Stent System II (DURABILITY II). J Vasc Surg. 2013;58:73-83.e1.

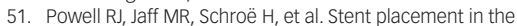
superficial femoral and proximal popliteal arteries with the innova self-expanding bare metal stent system. Catheter Cardiovasc Interv. 2017;89:1069-77.

52. ClinicalTrials.gov. SuperNOVA Clinical Stenting Trial. ClinicalTrials.gov Identifier: NCT01292928. Available at: https://clinicaltrials.gov/ct2/show/NCT01292928 (accessed 5 July 2021).

53. Krankenberg H, Schlueter M, Steinkamp HJ, et al. Nitinol stent implantation versus percutaneous transluminal angioplasty in superficial femoral artery lesions up to $10 \mathrm{~cm}$ in length: the femoral artery stenting trial (FAST). Circulation. 2007;116:285-92.

54. Bosiers M, Torsello G, Gissler H-M, et al. Nitinol stent implantation in long superficial femoral artery lesions: 12-month results of the DURABILITY I study. J Endovasc Ther. 2009;16:261-9.

55. Schroeder H, Meyer D-R, Lux B, et al. Two-year results of a low-dose drug-coated balloon for revascularization of the femoropopliteal artery: outcomes from the ILLUMENATE first-in-human study. Catheter Cardiovasc Interv. 2015;86:278-86

56. Rosenfield K, Jaff MR, White CJ, et al. Trial of a paclitaxel-coated balloon for femoropopliteal artery disease. N Eng/ I Med. 2015;373:145-53

57. ClinicalTrials.gov. Moxy drug coated balloon vs. standard balloon angioplasty for the treatment of femoropopliteal arteries (LEVANT 2). ClinicalTrials.gov Identifier: NCT01412541. Available at: https://clinicaltrials.gov/ct2/show/NCT01412541 (accessed 5 July 2021). 


\section{Review Devices}

58. Langhoff R, Arjumand J, Waliszewski $\mathrm{M}$, et al. The real-world CONSEQUENT ALL COMERS Study: predictors for target lesion revascularization and mortality in an unselected patient population. Angiology. 2021;72:724-32.

59. Scheinert D, Duda S, Zeller T, et al The LEVANT I (Lutonix paclitaxel-coated balloon for the prevention of femoropopliteal paclitaxel-coated balloon for the prevention of femoropop
restenosis) trial for femoropopliteal revascularization: first-in-human randomized trial of low-dose drug-coated balloon versus uncoated balloon angioplasty.

JACC Cardiovasc Interv. 2014;7:10-9.

60. ClinicalTrials.gov. LEVANT I, The Lutonix Paclitaxel-Coated Balloon for the Prevention of Femoropopliteal Restenosis (LEVANT I). ClinicalTrials.gov Identifier: NCT00930813. Available at: https://clinicaltrials.gov/ct2/show/NCT00930813 (accessed 5 July 2021).

61. Collins AJ, Foley RN, Herzog C, et al. Excerpts from the US Renal Data System 2009 Annual Data Report. Am I Kidney Dis.
2010;55:S1-A7.

2. ClinicalTrials.gov. Study Comparing Lutonix AV Drug Coated Balloon vs Standard Balloon for Treatment of Dysfunctional AV Fistur ClinicalTrias gov Identifer NCT02440022 Avilabe

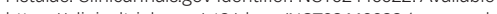
hettos./Clinicaltrils 25 June 2021)

63. Trerotola SO, Saad, TF, Roy-Chaudhury P, et al. The Lutonix AV randomized trial of paclitaxel-coated balloons in arteriovenous fistula stenosis: 2-year results and subgroup analysis. J Vasc Interv Radiol. 2020;31:1-14.

64. Uccioli L, Meloni M, Izzo Very, et al. Critical limb ischemia: current challenges and future prospects. Vasc Health Risk Manag. 2018;14:63-74

65. ClinicalTrials.gov. Investigating the Safety and Efficacy of the Treatment With Luminor DCB and Angiolite DES of ivascula in TASC C and D Tibial Occlusive Disease in Patients With Critical Limb Ischemia (MERLION). ClinicalTrials.gov Identifier:
NCT04073121. Available at: https://clinicaltrials.gov/ct2/show/ NCT04073121 (accessed 25 June 2021).

66. ClinicalTrials.gov. AcoArt II/ BTK China: Drug-eluting Balloon for Below-The-Knee Angioplasty Evaluation in China. ClinicalTrials. gov Identifier: NCT02137577. Available at: https://clinicaltrials. gov Identifier: NCT02137577. Available at: https://clinical
gov/ct2/show/NCT02137577 (accessed 25 June 2021).

67. Jia X, Zhuang B, Wang F, et al. Drug-coated balloon angioplasty compared with uncoated balloons in the treatment of infrapopliteal artery lesions (AcOArt II-BTK). J Endovasc Ther. 2021;28:215-21

68. Freisinger E, Koeppe J, Gerss J, et al. Mortality after use of paclitaxel-based devices in peripheral arteries: a real-world safety analysis. Eur Heart J. 2020;41:3732-9.

69. Roiron C, Sanchez P, Bouzamondo A, et al. Drug eluting stents: an updated meta-analysis of randomised controlled trials. Heart. 2006;92:641-9. 